\title{
Trousseau's syndrome associated with tissue factor produced by pulmonary adenocarcinoma
}

\author{
T Sato, I Tsujino, D lkeda, M leko, M Nishimura
}

Thorax 2006:61:1009-1010. doi: 10.1136/thx.2004.031492

The case history is presented of a patient with Trousseau's syndrome in which tissue factor originating from lung cancer appeared responsible for recurrent DVT/PE. This is thought to be the first such case to be reported.

V nous thrombosis was identified as a complication of cancer by Trousseau in 1865, and the combination of the two conditions is still often called Trousseau's syndrome. ${ }^{1}$ Although the precise mechanism of this syndrome is not fully understood, we present a case in which tissue factor (TF) originating from lung adenocarcinoma appeared responsible for recurrent deep vein thrombosis (DVT) and pulmonary thromboembolism (PE).

\section{CASE REPORT}

In April 2002 a 31 year old man presented to a nearby hospital with dry cough and dull pain in the right leg and was diagnosed as having DVT and PE. Although warfarin was commenced and prothrombin time-international ratio (PTINR) was optimal, DVT recurred in the left leg in December 2002 and in the right subclavian vein in February 2003. He was reviewed by a haematologist to rule out coagulation and fibrinolytic abnormalities; however, no such findings were evident. Unfractionated heparin was administered and the patient did not experience further thrombotic or embolic complications while on this treatment. He was referred to our hospital for further investigation in July 2003.

He had no history of cigarette smoking and of inhalation of toxic substances. Laboratory data on admission indicated mildly raised white cell count $\left(10500 / \mathrm{mm}^{3}\right)$ and slight anaemia (haemoglobin $10.9 \mathrm{~g} / \mathrm{dl}$ ). Coagulation studies (under continuous heparinisation 10000 units daily) revealed hypercoagulopathy and hyperfibrinolysis (thrombin-antithrombin complex $19.0 \mathrm{ng} / \mathrm{ml}$, fibrinogen/fibrin degradation products $87.5 \mu \mathrm{g} / \mathrm{ml}$, D-dimer $48.5 \mu \mathrm{g} / \mathrm{dl}$, and plasmin- $\alpha_{2}$-plasmin inhibitor complex $10.0 \mu \mathrm{g} / \mathrm{ml}$ ). Protein C and protein $S$ levels were normal and both lupus anticoagulant and anti-cardiolipin- $\beta_{2}$-glicoprotein I complex antibody were negative.

A chest radiograph revealed a left pleural effusion and a nodule in the left lower lung field. A CT scan of the chest indicated a $30 \times 20 \mathrm{~mm}$ mass in segment 8 (S8) of the left lower lobe with hilar and mediastinal lymphadenopathy. Perfusion scintigraphy using ${ }^{99 \mathrm{~m}} \mathrm{Tc}$ showed multiple perfusion defects in both lungs, suggesting multiple PE. ${ }^{18} \mathrm{~F}-$ fluoro-2-deoxyglucose positron emission tomography revealed positive uptake in the systemic lymph nodes, vertebral bone, and also at the site of the left pulmonary tumour. At fibreoptic bronchoscopy the endothelium of the left main bronchus appeared granular and histopathological analysis of a biopsy specimen obtained from this site revealed adenocarcinoma, leading to a clinical diagnosis of primary lung adenocarcinoma of the left S8 origin with clinically T4N3Ml stage IV.

To gain insight into the underlying mechanism of recurrent DVT and PE, we measured plasma levels of interleukin $1 \beta$ (IL-1 $\beta$ ), tumour necrosis factor $\alpha(\mathrm{TNF} \alpha)$, and TF, all of which are considered to induce a procoagulant state, particularly in patients with malignancy. The serum level of IL- $1 \beta$ was within normal limits $(<10 \mathrm{pg} / \mathrm{ml}$; normal range $<10 \mathrm{pg} / \mathrm{ml}$ ) and that of $\mathrm{TNF} \alpha$ was only slightly raised (8 pg/ $\mathrm{ml}$; normal range $<5 \mathrm{pg} / \mathrm{ml}$ ). However, the plasma TF level (IMUBINED Tissue Factor ELISA Kit, American Diagnostica Inc, Greenwich, CT, USA) was markedly higher than that found in healthy individuals and than levels seen in lung cancer patients without thromboembolic disease (fig 1). Furthermore, immunohistochemical study of the left main bronchus specimen using monoclonal anti-TF antibody (monoclonal antibodies against human tissue factor (murine $\mathrm{IgG}_{1}$ selection; American Diagnostica Inc) was positive, indicating production of TF in the malignant tissue (fig l).

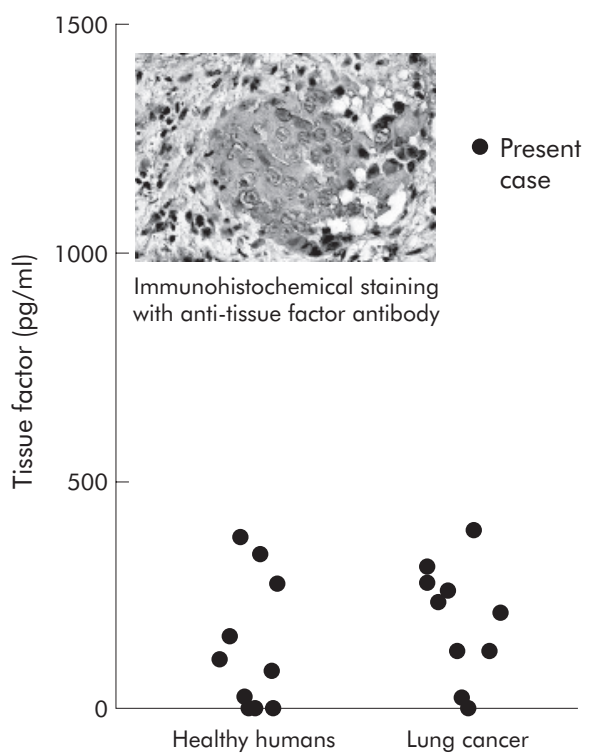

Figure 1 Plasma levels of tissue factor (TF) in healthy humans, the present case, and lung cancer patients without thromboembolic disease. The plasma TF level was markedly higher in the present case than in healthy humans $(n=10)$ and in lung cancer patients without thromboembolic disease $(n=10)$. In addition, immunohistochemical staining of the specimen using monoclonal anti-TF antibody was positive, indicating production of TF in the malignant tissue.

Abbreviations: DVT, deep vein thrombosis; PE, pulmonary embolism; TF, tissue factor 


\section{DISCUSSION}

Several molecules have been considered as candidates in the pathogenesis of Trousseau's syndrome. These include several cytokines (IL-1 $\beta, T N F \alpha$, and IL-6), cancer procoagulant, and $\mathrm{TF}^{2}$ In the present case a marked increase was seen in the plasma TF level, together with positive staining of cancer cells with monoclonal anti-TF antibody. This led us to believe that TF originating from the lung adenocarcinoma might played a pivotal role in the pathogenesis of recurrent DVT/PE in the present case.

In human non-small cell lung cancer, several studies have documented the expression of TF protein and/or mRNA in malignant cells or tissue. ${ }^{3-5}$ However, although significant relationships between TF and metastasis and/or angiogenesis were noted, none of these studies focused on the role of TF in the pathogenesis of concomitant DVT/PE. Moreover, recent reports highlighting the complication of PE in lung cancer did not explore the underlying thromboembolic mechanisms. ${ }^{6}$ This is the first report to show the possible contribution of TF in the pathogenesis of DVT/PE in patients with lung cancer.

Interestingly, DVT and PE recurred during warfarin treatment but not during intravenous infusion of unfractionated heparin. Heparin has several antithrombotic mechanisms that warfarin lacks, such as release of tissue factor pathway inhibitor from endothelial binding sites. This might explain the more favourable effect of heparin compared with warfarin in the present case. Indeed, several studies have shown higher recurrence rates of venous thromboembolism in cancer patients treated with warfarin than in those treated with heparin. ${ }^{8}$

In conclusion, a review of the literature suggests that this is the first reported case of Trousseau's syndrome in which TF originating from lung cancer appeared responsible for recurrent DVT/PE. Further accumulation of similar cases is warranted to define the precise role of TF in this syndrome.

\section{Authors' affiliations}

T Sato, I Tsujino, D Ikeda, M Nishimura, First Department of Medicine, Hokkaido University School of Medicine, Hokkaido, Japan

M leko, Department of Internal Medicine, School of Dentistry, Health

Sciences, University of Hokkaido, Hokkaido, Japan

Competing interests: none declared.

Correspondence to: Dr I Tsujino, First Department of Medicine, Hokkaido University School of Medicine, Kita 15 Nishi 7, Kita-ku, Sapporo, Hokkaido, Japan 060-8638; ił013@med.hokudai.ac.jp

Received 18 August 2004

Accepted 11 October 2004

\section{REFERENCES}

1 Trousseau A. Phlegmasia alba dolens. Clin Med Hotel-Dieu Paris 1865:3:654-712.

2 Bick RL. Cancer-associated thombosis. N Engl J Med 2003;349:109-11.

3 Koomagi R, Volm M. Tissue-factor expression in human non-small-cell lung carcinoma measured by immunohistochemistry: correlation between tissue factor and angiogenesis. Int J Cancer 1998;79:19-22.

4 Sawada M, Miyake S, Ohdama S, et al. Expression of tissue factor in nonsmall cell lung cancers and its relationship to metastasis. Br J Cancer 1999;79l:472-7.

5 Minamiya Y, Matsuzaki I, Sageshima M, et al. Expression of tissue factor mRNA and invasion of blood vessels by tumor cells in non-small cell lung cancer. Surg Today 2004;34:1-5.

6 Di Micco P, Coppola L, Diadema MR, et al. Internal jugular vein thrombosis as first sign of metastatic lung cancer. Tumori 2003;89:448-51.

7 Behrendt CE, Ruiz RB. Venous thromboembolism among patients with advanced lung cancer randomized to prinomastat or placebo, plus chemotherapy. Thromb Haemost 2003;90:734-7.

8 Sack GH Jr, Levin J, Bell WR. Trousseau's syndrome and other manifestations of chronic disseminated coagulopathy in patients with neoplasms: clinical, pathophysiologic, and therapeutic features. Medicine 1977;56:1-3. 